\title{
FORMATION AND ANALYSIS OF REGULATED AND FREELY NEGOTIATED PRICES OF ELECTRICITY IN BULGARIA
}

\author{
J. Angelova* \\ Department of Economics, Industrial Engineering and Management, \\ Faculty of Management, Technical University of Sofia, Bulgaria
}

\begin{abstract}
Moving from a state monopoly to a competitive environment is a major challenge for all energy companies. Under a regulated market, the recognition of costs passes through the regulator regardless of how effective the spending of the funds is. By creating a free energy market, it aims at streamlining production costs, improving energy efficiency and introducing competition in the sector.

For the purpose of the analysis, information on the free market price chain is used and an analysis of the share distribution of the network component with VAT and excise is made.
\end{abstract}

Key words: Electricity Market; Balancing group; Network Component; Electricity Market

\section{FORECAST AND ANALYSIS OF REGULATED ELECTRICITY PRICES IN BULGARIA}

It is known that the cost of electricity (EE) is formed by a number of factors. In order to reach the option paid by the final consumer, it passes through the main energy vertical actors, namely producers, transmission companies, distribution and supply companies. In order to understand the logic of pricing, we need to analyze the cost of each stage and the weight that falls on each actor in the chain.

Another point to be taken into account when analyzing the analysis are the different markets at which the final price is formed. There are currently two parallel operating segments of the electricity market - a regulated and liberalized market.

According to the requirements of the European directives, the prices that are obligatorily regulated in a liberalized market are the network prices, ie. Prices for transmission and distribution of EE.

Regulating energy prices is considered as a possible option, but for a transitional period and with a damping effect, if such is necessary

\footnotetext{
*Correspondence to: Jordanka Angelova, Department of Economics, Industrial Engineering and Management, Faculty of Management, Technical university of Sofia, Bulgaria, e-mail: jsa@tu-sofia.bg
}

in order to protect vulnerable consumers and if there are no conditions for competition.

Regulated prices are required to ensure:

- Sufficient revenue to enable the company to exist and develop;

- Resource efficiency incentives;

- Proper price alerts to users.

The regulated EE prices are determined in accordance with the Ordinance on the Regulation of the EE Prices [4] and are approved by a decision of the CESR for each regulatory period.

According to the latest amendments to the Energy Law [2], prices are subject to the following:

- the producers, within the limits of the availability of the commission under Article 21, paragraph 1, item 21, sell EE to the public provider;

- producers sell heat to the heat transmission company and to directly connected customers;

- The heat transfer company sells heat to customers;

- The public provider sells EE to the transmission and distribution system operators to cover transmission technology costs;

- The public supplier sells to the end suppliers the redeemed on the grounds of Art. 21, para. 1, item $21 \mathrm{EE;}$ 
- The public supplier sells natural gas to the end suppliers of natural gas and customers connected to the gas transmission network;

- End suppliers sell natural gas to customers connected to the respective gas distribution networks;

- End suppliers sell EE to residential and non-residential end customers for sites connected to a power distribution network at a low voltage level;

- For access and / or transmission through the transmission grid;

- To join the networks;

- Access and transmission of natural gas through transmission and / or distribution networks, except in cases where the Commission at its discretion approves a methodology for setting the price for access and transmission over a transmission network;

- For access and / or transmission through power distribution networks;

- For access and storage of natural gas in a storage facility;

- For distribution of traction EE on the distribution networks of the railway transport;

- The services provided to clients by the Commission, related to the licensed activity;

- Including the price or cost component through which all end customers connected to the electricity system participate in the compensation of costs under Art. 35 of the Energy Law.

According to the Energy Law [2], EEE prices are reviewed and updated annually within the so-called " A price period covering one year from 1 July of the current year to 1 July of the following year, and the Energy and Water Regulatory Commission (CESR) may, if necessary, amend the approved EE prices during the price period, often once per calendar quarter.

In order for the Regulator to make accurate price updates, it performs an analysis and assessment of: the reported overall financial position of the respective energy enterprise; of the forecasted technical and economic indicators validated in the prices and reported for the period; Of the achieved quality indicators.

The principles of pricing are interdependent and a balance is needed which is very difficult to achieve. They relate to:

- Reimbursement of costs;

- Simplicity;

- Transparency;

- Non-discrimination;

- Social tolerance;

- Political acceptability / consensus.

\section{METHODOLOGY FOR FORMING PRICES. BULGARIAN PRICE ADJUSTMENT MODEL}

In order to be able to prove their costs, energy companies are required to provide the CESR with justification and evidence of all costs that are included in the price of energy.

For the purpose of price regulation, the estimated costs do not include:

- costs associated with the sale of energy at freely negotiated prices;

- costs not related to the licensing activity;

- costs not incurred in the interests of consumers;

- taxes related to corporate income tax;

- sanctions and / or fines imposed by state authorities or by the Commission, as well as default interest, penalties and other payments related to non-performance of other contracts.

Incentive regulation can be defined as a "half way" of regulation by a rate of return to full competition. It repeats the behavior of the competitive market and provides the best incentives to reduce losses.

Additional regulations are needed to guarantee the quality of services.

The Bulgarian model of regulation combines the two main types of regulation - standard regulation and incentive regulation (Figure 1).
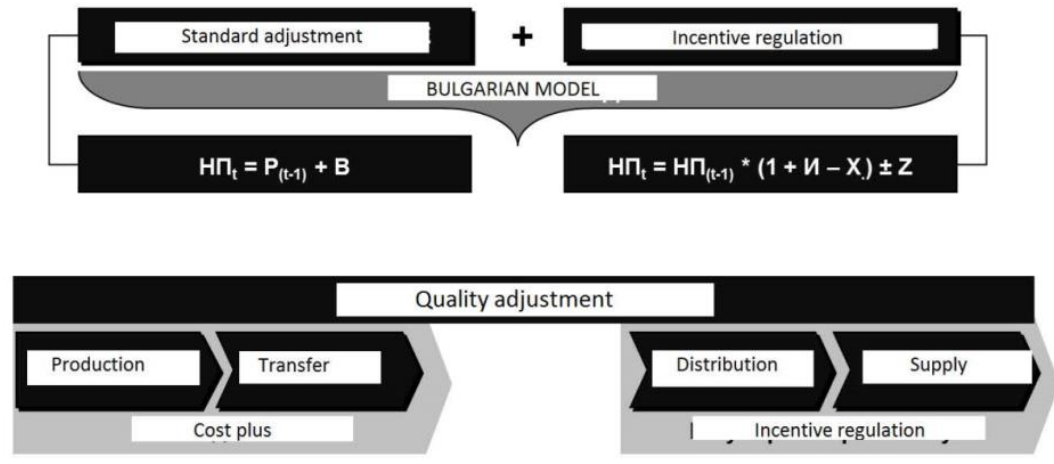
In Bulgaria, EE prices are regulated by the CESR until the necessary level of competition is in place, allowing the market to be freely negotiated. The CESR applies a variety of cost-pricing methods to licensed energy companies. Regulatory methods still applied to some energy companies "reward" inefficient energy companies and "punish" those who work effectively due to mechanical coverage of actual individual costs, regardless of the potential for efficiency. There is also a lack of complex tariff systems that correctly target the behavior of producers and consumers. This has necessitated the amendments to the EAAAA [7] as regards the Commission's ability to regulate prices by applying different regulatory methods, including defining performance indicators for energy companies, indicators of comparability between them, fulfillment of baseline criteria.

Measures have been introduced to protect consumers in the context of full liberalization of the electricity market. For sites connected to a power distribution network at a low voltage level owned by residential and non-residential end-users, provision is made for $\mathrm{EE}$ at regulated prices. For this purpose, the KEU sets out EE allowances which each producer is obliged to sell at regulated prices with a view to supplying vulnerable consumers.

According to the Energy Act, the KEVR sets quotas for the electricity producers, which they have to sell to the public supplier at regulated prices for the needs of the "protected consumers". The remaining quantity produced can be traded on the free market.

\section{FORMING AND ANALYSIS OF FREE} RENOVATED EE PRICES IN BULGARIA

As mentioned, in line with the EU Directive 2003/54 / EC and repealed by Directive 2009/72 / EC [1] for establishing a single internal energy market, Bulgaria has undertaken commitments to fully liberalize its energy sector. Moving from a state monopoly to a competitive environment is a major challenge for all energy companies. Under a regulated market, the recognition of costs passes through the regulatory body regardless of how effective the spending of the funds is. By creating a free energy market, it aims at streamlining production costs, improving energy efficiency and introducing competition in the sector.

Under the provisions of the Energy Law [2], manufacturers, EEE traders and business users connected to medium and high voltage may enter into EEE at freely negotiated prices under the terms of the regulations and in accordance with the EE Trading Rules [5]. They could enter into EE import or export transactions with persons registered in another country only in the following circumstances:

- The other state and the Republic of Bulgaria are members of the European Union;

- An agreement has been reached between the other country and the Republic of Bulgaria under an international act on the mutual enforcement of the relevant European Community law by recognizing the right to free trade in EEs under the legislation of the other country .

Once the above circumstances arise, the ability to negotiate freely negotiated prices will increase sharply. The increase in the number of transactions on the liberalized EE market implies aggressive competitive behavior by end suppliers as with the outflow of more consumers on the free market, the volume of sales made by the respective public supplier will decrease almost reciprocally. There are other business organizations that take away part of the market (supply of electricity for heating). These are District Heating Companies, Firms for Supply of Solid Fuels and Gas, Petroleum Products and others.

Typical of this free market is that customers can choose between two forms of delivery either to go directly to the free market or to take advantage of the services of a Last Instance Supplier (NPI) whose role is to supply EE customers who cannot or have not chosen an energy supplier. In the first case the price will be determined entirely by market mechanisms and in the second by a special methodology that has to be approved by the energy regulator but will not be lower than the regulated prices. The second type of sale cannot be fully attributed either as a free market transaction (not subject to free negotiation, not subject to balancing due to lack of hourly measurement facilities) nor as a sale at regulated prices.

The price of EE on the free market is formed on the basis of a demand-supply ratio for each specific period. The difficulty in determining the EE's estimated cost stems from the multicomponent EE price and the expected price changes for transmission and access over the transmission and distribution networks [6].

Figure 2 presents the multi-component price of EE on the free market. 


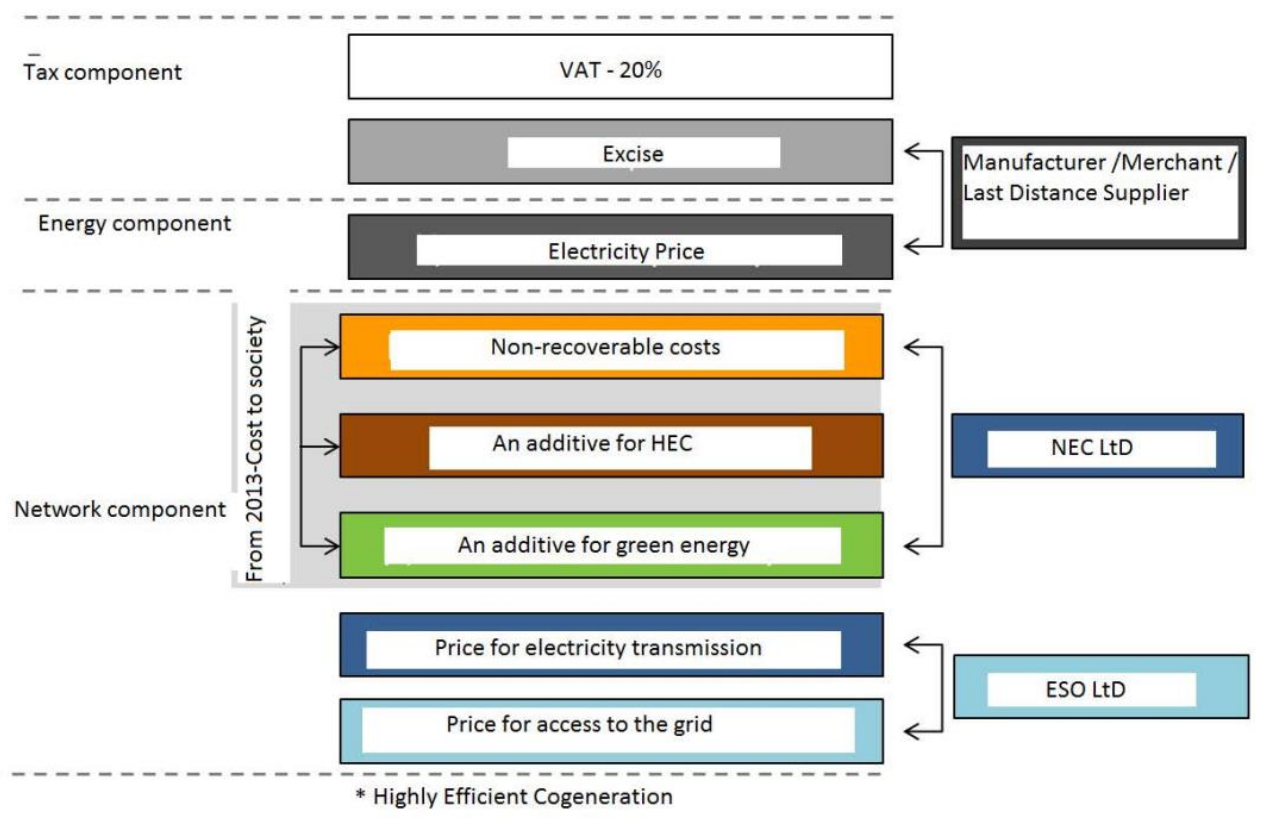

Figure 2. The free market price chain

The final price is the sum of the tax, network and energy components. The tax component includes Value Added Tax (VAT) and accrued excise duty. VAT is charged by all participants, whereas excise duty is charged only by the manufacturer or trader, and then, under the Excise Duties and Tax Warehouses Law [3], must be paid to the Customs Agency. In the end, the user who pays the excise is the consumer.

The network component includes: Price for access to the electricity network, which is charged by ESO EAD; High voltage transmission price; Green energy supplement; High Efficiency Cogeneration Supplement and effective from 1 July 2012 Price for "nonrecoverable costs" charged by NEK EAD.

The energy component includes the EE price, which is determined on a market-based basis, depending on supply and demand.

The value of the network component is not a market indicator, because it is determined by the CERV and not the market conditions. From 2007 to 2012, it rose from 17.16 BGN / MWh. Up to 43.51 BGN / MWh. In 2013, the network component drops to $\$ 30.34$ / MWh. And in 2014 again rises to 34.69 BGN / MWh. Overall, it remains $20 \%$ below the 2012 value. VAT is a constant figure and represents $20 \%$ of all other items. The excise value increases from \$ 1 / MWh. In 2007 to BGN 2 / MWh. In 2010 (100\% growth), then retaining the level until 2014 inclusive.

By 2014, the greatest burden on the value of the network component is the cost of debt to the public. It represents $55 \%$ of the total value of the component. This component was introduced in 2013, replacing the green, brown, and non-renewable costs. When it was introduced in 2013, its share was $44 \%$. Next is the high-voltage transmission cost, which is $19 \%$ of the total value in 2014. During the period under review, its share has been steadily declining, as in 2007 it was $48 \%$. Thirdly, the VAT is constant as a share in the period and represents $17 \%$ of the total value. The share of excise duty is relatively constant and by 2014 it is $6 \%$ of the total. The price for access to the transmission network has the lowest share in 2014. It was $30 \%$ in 2007 and only $4 \%$ in 2014.

The prices for the conclusion of EE purchase and sale contracts between the commercial participants (producers, through their free availability, free-market users and traders) are negotiated freely.

For the purpose of balancing production and consumption, ESO EAD organizes a balancing energy market. The parties to the balancing energy contracts are the commercial actors (consumers, traders, producers) and the public supplier, on the one hand, and ESO EAD, on the other. The company balances the system on the basis of proposals received on the balancing market, taking into account agreements between producers and consumers.

\section{FORMING THE EE PRICES IN A BALANCING GROUP IN BULGARIA}

The market model with the formation and actual functioning of the balancing groups was launched in September 2012. 
Figure 3 illustrates the difference between individual balancing and balancing in a balanced group. Individual balancing is related to the commitment of users to balance themselves by exchanging balancing energy in the balancing market. The balancing group brings together several participants who participate in the balancing market in general.

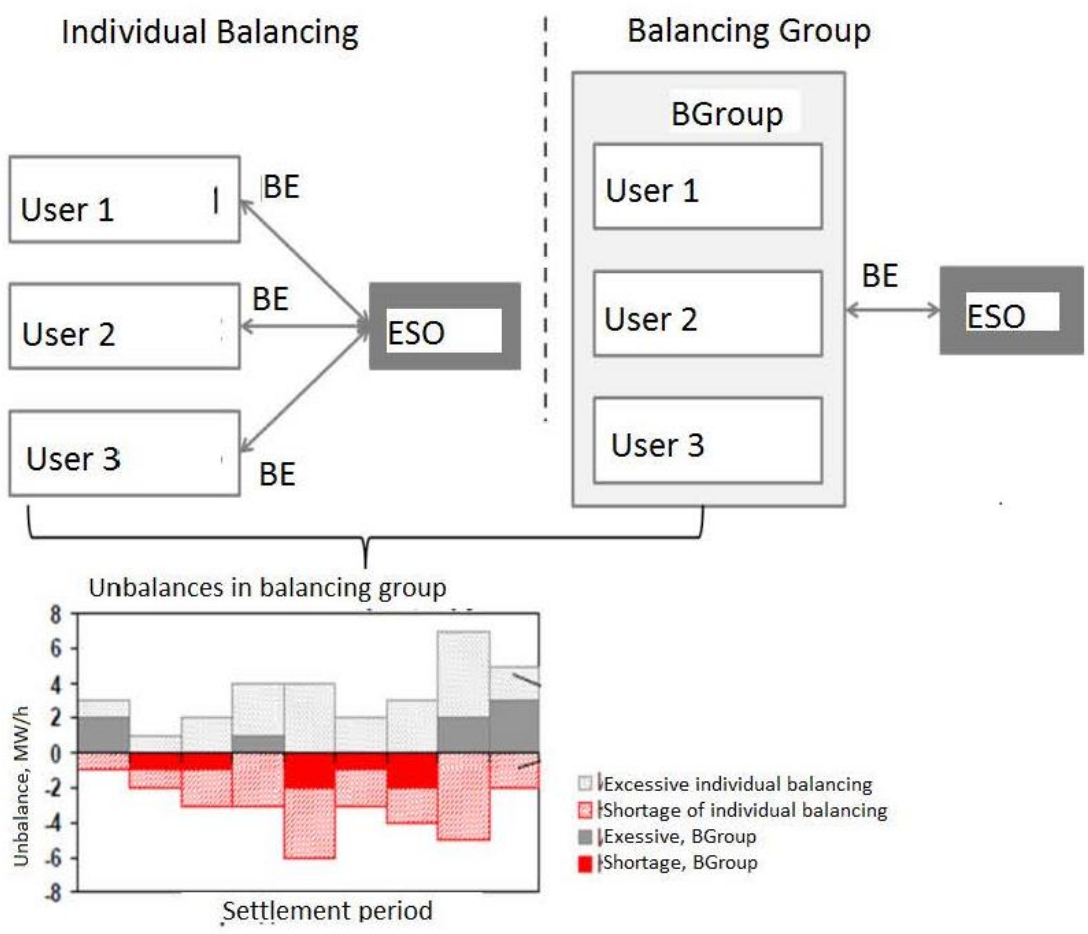

Figure 3. Balancing group

The idea of balancing groups is to aggregate the imbalances of trading participants and mitigate the economic consequences of balancing energy prices.

Business users on the free market usually enter into one-year purchase or sale contracts with a trader or EE producer indicating the intended consumption on both an annual and monthly basis. They can now manage their consumption by sending a daily payment schedule request for two days before the actual delivery, which they can correct up to a day before receiving the requested daily quantities. It is very difficult to predict real consumption with $100 \%$ accuracy due to a number of factors, and even with the help of energy management systems, enterprises are performing less but still unbalanced. These imbalances are realized on the balancing market, respectively, as a shortage, which is additionally purchased as a surplus sold on the balancing market.

As of January 2015, the price at which the balancing market participants sell their excess energy is $27.89 \mathrm{BGN}$ per $\mathrm{MWh}$, while their cost is BGN 186.65 per MWh. The average free market price for the same period varies between 73 and 87 leva (depending on the type of EE purchased), so that every poorly predicted megawatt hour of industrial users is spreading solid losses. The imbalances raise the $\mathrm{EE}$ price for large industrial enterprises between BGN 2 and BGN 6 per megawatt hour, depending on how successful they have estimated their consumption.

By transferring surpluses and shortfalls between individual members in the group, the balancing group coordinator will be able to reduce these differences. According to the trader, within a few months of the start of the test phase of the balancing groups in September 2012, the group members' shortage has fallen between $58 \%$ and $78 \%$, and these indicators are retained in 2015. The surpluses of the group coordinated by the trader fell from $16 \%$ to $39 \%$. The trader's expectations are that the final price for members in the group drops by BGN 2.6 per MWh.

\section{CONCLUSION}

An analysis of the prices, their variation and the weight on the total price by elements of the network and the tax component were made. The energy component is not considered because EE prices are determined on a marketbased basis and are individual for individual market participants. 
The author is of the opinion that a lack of transparency and sufficient awareness of pricing methods deprives end-users of the correct price evaluation they pay.

Due to the specificity and structure of the tariffs of customers connected to the high voltage grid, the free market is economically the most profitable for large industrial users. The difference between the free market price and the cost of customers' High voltage (HV) on a regulated market is minimal and therefore accurate planning of the schedules is necessary in order to lower the cost of the imbalances.

Currently, the market for freely negotiated prices is still limited and is accompanied by a number of problems to be overcome. In this connection, some suggestions for more basic requirements for the functioning of a balancing group can be made, namely:

- In order to form a balancing group it is necessary to have at least 2 members with similar consumption;

- The balancing group must have its own balancing rules to be determined by the Balancing Group Coordinator (KGB) and synchronized with the members;

- It is necessary to have a chosen pattern of distribution of the imbalances, which are defined by the KGB and synchronized with the members;
- $\quad$ Balancing energy prices in the group should be attractive for the participants and profitable for the KGB;

- The communication between the participants in the group should be timely and correct.

\section{REFERENCES}

1. Direktive 2009/72/EO in EU from 13.07. 2009 , on common rules for thr internal market in Electricity and repealing Directive 2003/54/EO

2. Energy Law, N07/09.12.2003.

3. Metodology for determining the prices of the balancing energy, An annex to 105, al.4 from Rules for trade in Electricity, DV.br. 39/09.05.2014

4. Naredba № 1/14.03.2017 г. za regulirane na cenite na electricheskata energia

5. Plan for the development of the transmission grid in Bulgaria in the period $2010-2020$ г.,

6. Stoilov D., Analysis of the electricity market in Bulgaria, Technical University Sofia, 2013.

7. Zakon za izmenenie i dopalnenie na Zakona za energetikata ot 22.07.2015 